\title{
Nurses Practice Regarding Post-operative Wound Care And Its Associated Factors Of Hospitalised Patients In Public Hospitals Of Mekelle City, Tigray, Ethiopia, 2018/19.
}

girmay legass tela ( $\square$ girmay888@yahoo.com )

Mekelle University

yohanss tesfay abebe

Mekelle University

kibrom berhanu $\mathbf{g}$ /slassie

Mekelle University College of Health Sciences

kiros belay gebrekidan

Mekelle University College of Health Sciences

Research article

Keywords: Practice, post-operative, wound care

Posted Date: May 19th, 2020

DOI: https://doi.org/10.21203/rs.3.rs-28833/v1

License: (c) (1) This work is licensed under a Creative Commons Attribution 4.0 International License.

Read Full License 


\section{Abstract}

Background: Post-operative wound care is a care that applied sterile gauze or bandage to wound to promote healing and protect the wound from further harm after surgical operation is done internally or externally to the involved organs. Post-operative Wound care is a nursing duty that requires excellent skills and knowledge to prevent massive complications such as infection, gangrene and amputation or, in severe cases, even death.

Methods: Hospital based cross sectional study design was implemented and the total sample size was 375 nurses working in Ayder Comprehensive Specialized Hospital, Mekelle Hospital and Quiha hospital. Pre-test was done on $10 \%$ of the sample size. Data was collected by observation and face to face interviewing using pre tested checklist and structured questionnaire respectively from March 20, 2019 to May 20, 2019. Simple random sampling was used. Data was coded, entered and analyzed using SPSS version 22.0 for statistical analysis. Binary logistic regression analysis was used to determine the predictor variables to the outcome variables with $95 \%$ confidence level at $p$-value of $<0.25$ and finally $p$ value $<0.05$ was described as statically significant.

Result: A total of 375 respondents were participated in the study. Among them, 234(62.4\%) were women. The overall nursing post-operative wound care practices were poor $258(68.8 \%)$. Work experience $(A O R=0.47,95 \% \mathrm{Cl} ; 0.26-0.86)$, level of education (AOR=0.03, 95\% $\mathrm{Cl} ; 0.004-0.25)$ and lack of materials $(A O R=0.29,95 \% \mathrm{Cl} ; 0.09-0.89)$ was found to be associated with nurses post-operative wound care practice.

Conclusion and recommendation: Factors such as work experience, educational level and lack of materials were statically significant association with nurses post-operative wound care practice. Highly qualified nurses should be engaged in training of other staff nurses in the tenderized dressing techniques of postoperative wounds.

\section{Background}

Wound care is defined as the application of fluid to a wound to remove exudates, slough, necrotic debris, bacterial contaminants and dressing residue without adversely impacting cellular activity vital to the wound healing process(1). The custom of post-operative wound care practice is as old as the history of surgery(2). It was started by washing the wounds by beer, making the plasters and bandaging the wound(3).

Approximately $10 \%$ of the hospitalized surgical patients suffers from surgical site infection in the world due to insufficient nursing postoperative wound care practice. Adequate level of skill and positive attitude are essential components in the delivery of post-operative wound care(4).

Effective wound care promotes wound healing and leads to early discharge and saving costs. The dressing protects the wound from injury, prevents introduction of bacteria, reduces discomfort, and 
speeds healing(5).Even to prevent such post-operative complications, it is necessary to study existing wound care practices and measure the difference between these and, ideally, to lean more towards evidence-based practices for wound care(6).

A surgical site infection is one of the most common causes of health care associated infection. It is also one of the most important complications of a surgical intervention. Certain factors are known to be responsible for surgical site infections. including application of skin antiseptics, inadequate sterilization of instruments, surgical hand's scrubs, and post-operative dressing techniques(7).

Postoperative wound infection is the leading infection in the general patient population in countries with limited resources, affecting up to two third of operated patients and with a frequency up to nine times higher than in developed countries. Postoperative wound infection accounts for about $15 \%$ of all healthcare-associated infections and about $37 \%$ of the hospital-acquired infections of surgical patients. In western countries, the frequency of such infections is $15-20 \%$ of all cases, with an incidence of $2-15 \%$ in general surgery. In Africa an incidence of surgical site infection ranging from $2.5-30.9 \%$ following various types of surgical procedures and up to $21 \%$ of operated patients develop wound infection in Ethiopia $(9,10)$.

\section{Methods}

\section{Study area and period}

The study was conducted in public Hospitals of Mekelle city, Tigray, Ethiopia

The study was conducted March 20, 2019 to April 20, 2019.

\section{Study design}

Institutional based cross -sectional study was employed.

\section{Source population}

All nurses working in post-operative Hospitalized Patients at the public hospitals of Mekelle city.

\section{Study population}

All selected nurses who are working in post-operative hospitalized Patients of the public hospitals of Mekelle city in the study period.

\section{Inclusion and exclusion criteria}

\section{Inclusion criteria}

All nurses working in post-operative hospitalized Patients at the public hospitals. 


\section{Exclusion criteria}

Nurses who were not directly involved in the bedside patient care such as head nurse and facilitator.

\section{Sample size determination and sampling technique}

The actual sample size for the study was determined by using the formula for single population proportion by assuming $5 \%$ marginal error (d), 95\% confidence interval and the proportion of poor nurses practice on post-operative wound care was taken $57.7 \%$ from previous study in Tanzania among nurses working in surgical wards. Based on the above information, the total initial sample size was calculated by using the formula.

$$
\mathrm{n}=\frac{\mathrm{Z}^{2} \mathrm{P}(1-\mathrm{P})}{\mathrm{d}^{2}}
$$

Where; $n=$ require initial sample size,

$Z=$ critical value for normal distribution at $95 \%$ confidence interval which equals to 1.96

$P=57.7 \%$, estimated proportion of nurses who had poor Practice on postoperative wound care.

$q=$ proportion of population practice of nurses on post-operative wound care $(1-0.577=0.423)$.

$d=$ the margin error between the sample and the population (0.05).

$$
\mathrm{ni}=\underline{(1.96)^{2} \times 0.577(1-0.577)}=375
$$

Since the source of population is few and to increase the representativeness, correction formula was not used and the study participants final sample size was 375 nurses.

\section{Sampling technique and Sampling procedure}

Simple random sampling method was employed to allocate the 375 study participants who are working in the wards during data collection period. Sampling process was based on lottery method

\section{Dependent variable}

- Nurses Post-operative wound care practice

\section{Independent variables}

- Socio demographic characteristics of nurses (Sex, Age, Level of education, Work experience)

- Institutional factors (Training, Work load, shortage of materials, Presence of protocol and standard) 
- Health care provider related factors ( opportunity to opinion, assertiveness and familiarity with antiseptic)

\section{Operational Definitions}

Practice - The application of standards and knowledge in to action (12).

Good practice - those who scored above the mean on practice items (9 and 14).

Poor practice - those who scored below the mean on practice items (9 and 14).

Post-operative - a period from patient is admitted to ward after having surgery till discharge home (28)

Wound care - dressing of wound using standard way (8).

\section{Data collection tool and technique}

Standard checklist and set of structured questionnaires by reviewing different literatures and modified by the researcher was used to collect the data after getting ethical clearance from IRB of Mekelle University. It was prepared in English then, the data were collected using observation and face to face interview from the study subjects. In this study BSc Nurses was collected data using a pretested checklist and questionnaire from the sample population according to the inclusion criteria. Four data collectors (BSc Nurses) from Mekelle Health Center and two supervisors ( $\mathrm{MScN}$ ) from Ayder comprehensive specialized Hospital was selected and they were participated throughout the data collection period.

\section{Data quality control}

Prior to data collection a two days training was given by the principal investigator. The training was supported by clearly prepared training manual and incorporated that; objectives of the study, introduction of checklist and questionnaire format, Procedure of observing and interviewing. To ensure quality of data, properly designed standardized data collection tool was used. Pre-test was conducted using $10 \%$ of the sample on nurse working in surgical ward in Wukro hospital before 2 weeks of the actual data collection period to assess instrument validity, simplicity, flow and consistency and questionnaire modification was made after the pretest accordingly

\section{Data processing and analysis}

The collected data was edit, check visually for its completeness and the response was coded, enter and analyzed using SPSS version 22.0.Descriptive statistics such as frequency, percentage mean and 
standard deviation was computed and the results was summarized and present by tables, charts and texts.

\section{Results}

\section{Socio- demographic characteristics of respondents}

A total of 375 nurses were involved in the study with the response rate of $100 \%$. Among the participants $234(62.4 \%)$ of them were females, the mean age and standard deviation of the participants was $33.98 \pm$ 6.12 with majority of $207(55.2 \%)$ of the nurses age was $25-34$ years, educational level of the study participants282 $(75.2 \%)$ of them had BSc degree in nursing. Regarding, work experience in the wards of the study participants majority 182(48.5\%) of them had from 2-5 years (As shown in Table 1).

Table 1

Socio - demographic characteristics of nurses working in Postoperative wound care at Mekelle Public Hospitals, Tigray, Ethiopia, $2019(n=375)$.

\begin{tabular}{|llll|}
\hline Variable & Category & Frequency & Percent (\%) \\
\hline \multirow{3}{*}{ Sex } & Male & 141 & 37.6 \\
\cline { 2 - 4 } & Female & 234 & 62.4 \\
& Less than 25 & 8 & 2.1 \\
\cline { 2 - 4 } & $25-34$ & 207 & 55.2 \\
\cline { 2 - 4 } & $35-44$ & 135 & 36.0 \\
\cline { 2 - 4 } Educational level & More than 44 & 25 & 6.7 \\
\cline { 2 - 4 } & Diploma & 81 & 21.6 \\
\cline { 2 - 4 } & BSc Degree & 282 & 75.2 \\
\cline { 2 - 4 } Work experience & less than 2 years & 126 & 3.2 \\
\cline { 2 - 4 } & 2-5yrs & 182 & 48.5 \\
\hline & $>5 y r s$ & 67 & 17.9 \\
\hline
\end{tabular}

\section{Nurse's practice on postoperative wound care}

More than half 201(53.6\%) of nurses were able to review physician order for dressing change procedures. Regards to documentation and teaching phase, documenting after dressing any signs of inflammation, infection or wound progress were done only by $3.7 \%$ of the participants followed by record of date and time $8.5 \%$ after the procedure (As shown in Table 2). 
Table 2

Nurses practice of post-operative wound care in Mekelle Public Hospitals, Tigray, Ethiopia, 2019( $n=375)$.

\section{Variable}

Review physician order for dressing change procedures

Prepare necessary equipment

Identify the patient

Explain procedure to the patient

Provide privacy

Patient's position comfortably

Wash hands and use face mask

Open sterile dressing sets on trolley (patient bedside)

Open bottle of antiseptic
basin
Wear disposable gloves

Remove and Dispose soiled dressing in disposable bag and apply mackintosh

Remove gloves by pulling out the inside of them

Put on sterile gloves
Category Frequency

(\%)

53.6

46.4

69.6

30.4

78.7

21.3

46.1

53.9

No $\quad 202$

9.1

Yes

34

90.9

No

341

46.1

Yes

173

(

No 202

53.9

Yes

104

27.7

No

271

72.3

Yes

211

56.3

No $\quad 164$

43.7

Yes

No

198

52.8

No $\quad 177$

47.2

Yes

256

68.3

No $\quad 119$

31.7

Yes

290

77.3

No $\quad 85$

22.7

Yes 201

No $\quad 174$

Yes

307

No

68
53.6

46.4

81.9

18.1 


\begin{tabular}{|c|c|c|c|}
\hline Variable & Category & Frequency & $\begin{array}{l}\text { Percent } \\
(\%)\end{array}$ \\
\hline \multirow{2}{*}{$\begin{array}{l}\text { Clean wound with antiseptic solution use gauze swab from least } \\
\text { contaminated area to most contaminated }\end{array}$} & Yes & 194 & 51.7 \\
\hline & No & 181 & 48.3 \\
\hline \multirow{2}{*}{$\begin{array}{l}\text { use a separate gauze swab for each stoke, applying antiseptic } \\
\text { ointment if ordered }\end{array}$} & Yes & 160 & 42.7 \\
\hline & No & 215 & 57.3 \\
\hline \multirow{2}{*}{$\begin{array}{l}\text { Use dry gauze to swab in same manner as in }(14,15) \text { to dry the } \\
\text { wound }\end{array}$} & Yes & 232 & 61.9 \\
\hline & No & 143 & 38.1 \\
\hline \multirow[t]{2}{*}{ Cover the wound with sterile gauze } & Yes & 362 & 96.5 \\
\hline & No & 13 & 3.5 \\
\hline \multirow{2}{*}{$\begin{array}{l}\text { Remove gloves and dispose in bag(change disposable glove } \\
\text { optional) }\end{array}$} & Yes & 50 & 13.3 \\
\hline & No & 325 & 86.7 \\
\hline \multirow[t]{2}{*}{ Apply tape over dressing (separate from drain) } & Yes & 320 & 85.3 \\
\hline & No & 55 & 14.7 \\
\hline \multirow[t]{2}{*}{ Assist patient to return to his/her comfortable position } & Yes & 48 & 12.8 \\
\hline & No & 327 & 87.2 \\
\hline \multirow[t]{2}{*}{ Dispose or return of supplies to their proper place } & Yes & 84 & 22.4 \\
\hline & No & 291 & 77.6 \\
\hline \multirow[t]{2}{*}{ Wash hands after procedure } & Yes & 47 & 12.5 \\
\hline & No & 328 & 87.5 \\
\hline \multirow{2}{*}{$\begin{array}{l}\text { Record Any sign of Inflammation or infection such as (hotness, } \\
\text { redness, swelling, tenderness, bad odor or pus) }\end{array}$} & Yes & 14 & 3.7 \\
\hline & No & 361 & 96.3 \\
\hline \multirow[t]{2}{*}{ Record date and time } & Yes & 32 & 8.5 \\
\hline & No & 343 & 91.5 \\
\hline
\end{tabular}


Table 3

Bivariate logistic regression analysis for socio demographic, professional and institutional associated factors of nurses practice post-operative wound care Mekelle public hospitals, 2019. $(n=375)$

\begin{tabular}{|c|c|c|c|}
\hline \multirow[t]{2}{*}{ Variables } & \multirow[t]{2}{*}{ Category } & \multicolumn{2}{|l|}{ OR } \\
\hline & & COR & $\begin{array}{l}P \leq \\
0.25\end{array}$ \\
\hline \multirow[t]{4}{*}{ Age } & less than 25 & 1 & 1 \\
\hline & $25-34 y r s$ & $\begin{array}{l}2.96(0.57- \\
15.39)\end{array}$ & 0.19 \\
\hline & $35-44 y r s$ & $0.88(0.37-2.11)$ & 0.79 \\
\hline & $>44$ yrs & $0.56(0.24-1.47)$ & 0.26 \\
\hline \multirow[t]{2}{*}{ Sex } & Male & 1 & 1 \\
\hline & Female & $1.05(0.67-1.65)$ & 0.81 \\
\hline \multirow[t]{3}{*}{ Work experience } & $\begin{array}{l}\text { Less than } 2 \\
\text { yrs }\end{array}$ & 1 & 1 \\
\hline & $2-5$ yrs & $0.49(0.26-0.91)$ & 0.025 \\
\hline & $>5 y r s$ & $0.48(0.26-0.85)$ & 0.013 \\
\hline \multirow[t]{3}{*}{ Educational level } & Diploma & 1 & 1 \\
\hline & Degree & $\begin{array}{l}0.04(0.005- \\
0.35)\end{array}$ & 0.003 \\
\hline & MSc & $\begin{array}{l}0.03(0.005- \\
0.28)\end{array}$ & 0.002 \\
\hline \multirow[t]{2}{*}{ Opportunities to demonstrate new practice } & Yes & 1 & 1 \\
\hline & No & $0.96(0.62-1.50)$ & 0.87 \\
\hline \multirow{2}{*}{$\begin{array}{l}\text { Is there lack of assertiveness in the health care } \\
\text { provider }\end{array}$} & Yes & 1 & 1 \\
\hline & No & $0.81(0.51-1.28)$ & 0.37 \\
\hline \multirow[t]{2}{*}{ Is there lack of Familiarity to antiseptic } & Yes & 1 & 1 \\
\hline & No & $1.35(0.74-2.48)$ & 0.31 \\
\hline \multirow[t]{2}{*}{ Training } & Yes & 1 & 1 \\
\hline & No & $0.71(0.41-1.23)$ & 0.23 \\
\hline \multirow[t]{2}{*}{ Work load effect in practice } & Yes & 1 & 1 \\
\hline & No & $1.99(0.89-4.47)$ & 0.09 \\
\hline
\end{tabular}




\begin{tabular}{|c|c|c|c|}
\hline \multirow[t]{2}{*}{ Variables } & \multirow[t]{2}{*}{ Category } & \multicolumn{2}{|l|}{ OR } \\
\hline & & COR & $\begin{array}{l}\mathrm{P} \leq \\
0.25\end{array}$ \\
\hline \multirow[t]{2}{*}{ Lack of materials effect in practice } & Yes & 1 & 1 \\
\hline & No & $0.32(0.11-0.95)$ & 0.04 \\
\hline \multirow[t]{2}{*}{ Protocol presence in the ward } & Yes & 1 & 1 \\
\hline & No & $2.11(0.7-6.40)$ & 0.18 \\
\hline \multirow[t]{2}{*}{ Effect of protocols in practice } & Yes & 1 & 1 \\
\hline & No & $1.45(0.79-2.63)$ & 0.22 \\
\hline
\end{tabular}

\section{Health care provider related associated factors}

Among the participants, majority of them 217 (57.9\%) responds that they have the opportunities to perform the new technique of post-operative wound care practice. Regards to lack of assertiveness $65.6 \%$ of the participant believes that there is lack of assertiveness and $14.4 \%$ of the participant said that there is lack of familiarity with antiseptics.

\section{Institutional related associated factors}

From a total of 375 participants, only $22.7 \%$ are taken a training related to post-operative wound care practice. Regards to work load $89.1 \%$ of the participants, said it affects the nursing practice, $96.3 \%$ of the participant respond that lack material affects wound care practice.

\section{Bi-variate logistic regression analysis}

The association of dependent variables with the independent variable was investigated using both bivariate and multivariable logistic regression technique. Bivariate logistic regression was done to assess the relationship between each independent variable with the outcome variable. The result reveals that age, work experience, Educational level, training, Work load effect, Lack of materials, Protocol presence and Effect of protocols found be significant predictors of nursing post-operative wound care practice at $P$-value of $\leq 0.25$. However; in this study there were no statistically significant relationships between nurses' sex, opportunities to demonstrate new practice, lack of assertiveness and lack of Familiarity to antiseptic towards post-operative wound care practice. Variables at $p$-value $\leq 0.25$ were transferred in to multivariate logistic analysis.

\section{Multi-variable analysis}

Multivariable logistic regression was done for post-operative wound care practice adjusted for all possible candidate predictors pooled from bivariate logistic regression at $p$ value $\leq 0.25$ analysis. In multivariate those at $p$ value $<0.05$ like work experience, educational level and lack of materials were found to be significant predictors of nurses post-operative wound care practice. Those who had more 
than five years of Work experience were $55 \%[\mathrm{AOR}=0.45 ; 95 \% \mathrm{Cl} ; 0.23-0.85]$ times less likely to have poor nurses practice of post-operative wound care as compared to those who had less than two years of work experience.

Those who were MSc holders were $97 \%$ [AOR = 0.036; $95 \% \mathrm{Cl} ; 0.004-0.29]$ times less likely to have poor nurses practice of post-operative wound care as compared to those who had diploma educational holders. Those who were do not have lack of materials during post-operative wound care practice were $71 \%[A O R=0.29 ; 95 \% \mathrm{Cl} ; 0.09-0.89]$ times less likely to have poor nurses practice of post-operative wound care as compared to those who were having lack of materials. 
Table 4

Bivariate and multivariate analysis for nurses' practice and its associated factors of post-operative wound care in Mekelle Public Hospitals, Tigray, Ethiopia, 2019 ( $n=375)$.

\begin{tabular}{|c|c|c|c|c|c|}
\hline \multirow[t]{2}{*}{ variables } & \multirow[t]{2}{*}{ Category } & \multicolumn{4}{|l|}{ OR } \\
\hline & & COR & $\begin{array}{l}P \text { value } \leq \\
0.25\end{array}$ & AOR & $\begin{array}{l}P< \\
0.05\end{array}$ \\
\hline \multirow[t]{4}{*}{ Age } & $\begin{array}{l}\text { less than } \\
25\end{array}$ & 1 & 1 & 1 & 1 \\
\hline & $25-34 y r s$ & $2.96(0.57-15.39)$ & 0.19 & $\begin{array}{l}2.83(0.48- \\
16.66)\end{array}$ & 0.25 \\
\hline & $35-44 y r s$ & $0.88(0.37-2.11)$ & 0.79 & $0.86(0.35-2.14)$ & 0.75 \\
\hline & $>44$ yrs & $0.56(0.24-1.47)$ & 0.26 & $0.64(0.25-1.67)$ & 0.37 \\
\hline \multirow[t]{3}{*}{ Work experience } & $<2$ yrs & 1 & 1 & 1 & 1 \\
\hline & $2-5$ yrs & $0.49(0.26-0.91)$ & 0.025 & $0.45(0.23-0.85)$ & 0.015 \\
\hline & $>5 y r s$ & $0.48(0.26-0.85)$ & 0.013 & $0.47(0.26-0.86)$ & 0.015 \\
\hline \multirow[t]{3}{*}{ Educational level } & Diploma & 1 & 1 & 1 & 1 \\
\hline & Degree & $\begin{array}{l}0.04(0.005- \\
0.35)\end{array}$ & 0.003 & $\begin{array}{l}0.03(0.004- \\
0.29)\end{array}$ & 0.002 \\
\hline & MSc & $0.03(0.005-0.28)$ & 0.002 & $\begin{array}{l}0.03(0.004- \\
0.25)\end{array}$ & 0.001 \\
\hline \multirow[t]{2}{*}{ Training } & Yes & 1 & 1 & 1 & 1 \\
\hline & No & $0.71(0.41-1.23)$ & 0.23 & $0.72(0.39-1.34)$ & 0.31 \\
\hline \multirow[t]{2}{*}{ Work load } & Yes & 1 & 1 & 1 & 1 \\
\hline & No & $1.99(0.89-4.47)$ & 0.09 & $2.13(0.90-5.03)$ & 0.08 \\
\hline \multirow{2}{*}{$\begin{array}{l}\text { Lack of } \\
\text { materials }\end{array}$} & Yes & 1 & 1 & 1 & 1 \\
\hline & No & $0.32(0.11-0.95)$ & 0.04 & $0.29(0.09-0.89)$ & 0.03 \\
\hline \multirow{2}{*}{$\begin{array}{l}\text { Protocol } \\
\text { presence }\end{array}$} & Yes & 1 & 1 & 1 & 1 \\
\hline & No & $2.11(0.7-6.40)$ & 0.18 & $0.55(0.17-1.74)$ & 0.31 \\
\hline \multirow[t]{2}{*}{ Protocol effect } & Yes & 1 & 1 & 1 & 1 \\
\hline & No & $1.45(0.79-2.63)$ & 0.22 & $1.57(0.81-3.05)$ & 0.17 \\
\hline
\end{tabular}


$A O R=$ adjusted odds ratio, $C O R=$ crude odds ratio, $95 \% \mathrm{Cl}=95 \%$ confidence interval

\section{Discussion}

In this study, nurses' post-operative wound care practice of 375 nurses working in admitted patients of Mekelle public hospitals were analyzed. Among the total Nurse, majority $258(68.8 \%)$ of them had poor post-operative wound care practice. This result was higher than a study done in Tanzania Muhimbili National Hospital were $57.7 \%$ (9) and Khartoum State Alamal hospital 23.4\%(13). This could be due to the difference in study population and staff commitment.

In the Preparation phase More than half (53.6\%) of nurses were able to review physician order for dressing change procedures. this is less than a Study done in Khartoum State Alamal hospital66.7\%(13). prepare necessary equipment's was done by $69.5 \%$, and there is a relatively similar result in TanzaniaMuhimbili National hospital64.8\% (9). Explain the procedure to patient or patient family was done by $46.1 \%$ which is lower than a study in Tanzania Muhimbili National hospital $81.7 \%(20)$ and Khartoum State Alamal hospital59\%(25). Provide privacy 9.1\%. its lower than a Study in Nigeria 83.3\% (15).Nurses hand washing before the procedures start was $27.7 \%$. Lower than Study in Tanzania Muhimbili National Hospital 49.3\%(9) and A study done in Kenya Mariakani cottage hospital $57.1 \%$ (17). This could be due to the difference in staff experience.

In the Applying of dressing technique phase, wear disposable glove to remove old dress was observed by $68.3 \%$ this is lower than a Study done in Tanzania Muhimbili National Hospitals 99\%(20). Put on sterile glove was done by $81.9 \%$,this is higher than a Study done in Tanzania Muhimbili National Hospital $63 \%$ (9).clean wound with antiseptic solution using gauze swab from least contaminated area to most contaminated 51.7\%,its higher than a Study done in Tanzania Muhimbili National Hospital 34\%,(9).Use separate gauze swab for each stroke $42.7 \%$,lower than a Study done in Khartoum State Alamal hospital $55 \%$ (26).Cover the wound with sterile gauze $96.5 \%$. its higher than a study done in Sudan Bahry Hospital $58.3 \%(16)$. This could be due to difference in material availability.

Regards to documentation and teaching phase, documenting after dressing any signs of inflammation, infection or wound progress were done only by $3.7 \%$ of the participants followed by record of date and time $8.5 \%$ after the procedure. This is better than a Study done in Tanzania Muhimbili National Hospital $0 \%(9)$ and lower than study done in Rwanda Butare Hospital $13 \%(8)$. This may be due to the different in nurse's habit towards documentation and hospital regulation.

Post-operative counseling and instructing the patient/relatives not to temper with the wound and nutrition was $13.6 \%$ of nurses. This result is Relatively similar with a Study done in Tanzania Muhimbili National Hospital 15\% (9).This may be due to the similarity in study design and study participants. And its lower than a Study done in Khartoum State Alamal hospital 33.3\%(13). This may be due to different study setting. Among the participants $14.4 \%$ of the answered that there is lack of familiarity with antiseptics. This result is lower than a study done in Mekelle public hospitals pediatric ward $26.6 \%(15)$. The possible 
difference may be due to the present study is wider in scope than the previous one as well as due to the instrument variation.

Work experience was significantly associated with poor nurses practice of post-operative wound care. This result is supported by the studies conducted in Nigeria (15) and Iraq (9).Educational level was also significantly associated with poor nurses practice of post-operative wound care. This result is supported by the findings conducted in Jaban Baghadad (19).Lack of materials is also significantly associated with poor nurses practice of post-operative wound care. This result is supported with the studies conducted in kenyataMarakani (17). The possible reason might be due to the similarity of study design.

\section{Conclusion}

Nurses' practice was observed good in covering of the wound with sterile gauze, however regards to recording of inflammation and infection was the lowest practice observed by nurses. Over all nurses' practice towards post-operative wound care was poor performance. Nurses Practice of post-operative wound care depends on work experience, educational level and lack of materials.

Based on the above finding of the study the following recommendations were made: -

1. Government and non-governmental health care organizations should come to the aid of those institutions by providing wound dressing equipment, employment/training of nursing personnel who are specialized in wound care.

2. Ministry of Health and the hospitals should ensure that nurses are more trained. This can be achieved by providing more learning opportunities to nurses.

3. Highly qualified nurses should be engaged in training other staff nurses in the tenderized dressing techniques of postoperative wounds.

4. Further Studies are recommended which incorporate larger and more diverse samples of nurses in order to have a wide understanding about this phenomenon.

\section{Limitation of the study}

Shortage of literature particularly studies on similar topics in our country could be mentioned as some of the limitations.

\section{Abbreviations}

ACSH: Ayder comprehensive specialized Hospital, AICU: Adult Intensive Care Unit, AOR: Adjusted Odds Ratio, CHS: College of Health Science ,DC: Data Collector, ETB :.Ethiopian Birr, GynW: Gynecology Ward ,MSc: Master of Science, PICU: Pediatric Intensive Care Unit, PWA: Pediatric ward A,PWB: Pediatric Ward B, SW: Surgical Ward, SWA: Surgical ward A,SWB: Surgical ward B,SPSS :Statistical Program for Social Sciences, WHO :World Health Organization 


\section{Declarations}

\section{Ethics approval and consent to participate}

Ethical clearance and approval was obtained from the institutional review board of Mekelle University CHS. Letters of permission was obtained from each hospitals Moreover, prior to conducting the study, the purpose and objective of the study was described to the study participants and written informed consent was obtained. The study participants were informed as they had full right to discontinue during the interview. Participants' confidentiality and any special data security requirements was maintained and assured by not exposing patients name and information. According the university ethical clearance rule and regulation, ethical clearance was obtained from institutional review board of Mekelle University (Reference number, MU/ 1266 /2019).

\section{Consent for publication}

Not applicable as there is no image or other confidentiality related issues.

\section{Availability of data and materials}

The datasets used during the current study is available from the corresponding author on reasonable request.

\section{Competing interests}

The author declares that they have no competing interests.

\section{Funding}

Mekelle University was the source of funding (refence No. 1266/2019).The University covers all payment issues related to the study (data collection-final).

\section{Author's contribution}

$\mathrm{YT}, \mathrm{KB}$ and $\mathrm{KB}$ make interpretation of the data and helping during analysis. GL prepares and submits the manuscript. All author have read and approved the manuscript.

\section{Acknowledgements}

Authors thanks to Mekelle University and the data collectors, supervisors and study participants.

\section{Author's information}

1. Girmay Legass, Department of Adult health nursing, Ayder Comprehensive specialized Hospital, Mekelle University, Tigray, Ethiopia. 
Phone no. +251914001888

2. Yohanns Tesfay, Department of RH and maternity, School of nursing, Mekelle University, Tigray, Ethiopia.

Email: johntesfay555@gmail.com

Phone no. +251914730560

3. Kibrom Birhanu, Department of RH and maternity, School of nursing, Mekelle University, Tigray, Ethiopia.

Email: kevybre@yahoo.com

Phone no. +251905000808

4. Kiros Belay, Department of Adult health nursing, School of nursing, Mekelle University, Tigray, Ethiopia.

Email: kirosbelayee@gmail.com

Phone no. +251902539059

\section{References}

1. Spencer Lenisa DS. Procedure of Wound Cleansing. Britsh Colomb Nurs J. 2017;2(6):24-6.

2. Gerald T. Lionelli, Lawrence WT. Wound dressings Gerald. Surg Clin N Am. 2012;83:617-38.

3. Shah JB. The History of Wound Care. J Am Col Certif Wound Spec. 2011;3(3):65-6.

4. Prática CE, Enfermeiros DOS, Cuidado SO, Feridas com. practice of nurses on the care of wounds. $j$ nurs. 2015;8(3):352-6.

5. Najm HY, Hussein RN. Assessment of wound dressing practices among nurses at the emergency hospitals in Erbil city. Zanco J Med Sci. 2018;22(1).

6. Ubbink DT, Brölmann FE, Go PMNYH, Vermeulen H. Evidence-Based Care of Acute Wounds: A Perspective. Adv Wound Care. 2015;4(5):286-94.

7. Famakinwa TT, Bello BG, Oyeniran, Y.A., Okhiah O and, R.N. N. Knowledge and practice of postoperative wound infection prevention among nurses in the surgical unit of a teaching hospital in nigeria. Int J Basic, Appl Innov Res. 2014;3(17):23-8.

8. Charalambous M. A Critical Exploration of Surgical-Oncology Nurse's Perceptions of Factors Involved in Decision Making on Postoperative Wound Management: 2014;3(1):10.

9. Mwakanyamale AA. Nursing practice on post operative wound care in surgical wards at muhimbili nationa hospital, dar-es-salaam, tanzania. 2013;7-8. 
10. WHO. Report on the Burden of Endemic Health Care- Associated Infection Worldwide .World Health Organization 2011.

11. Messele G, Woldemedhin Y, Demissie M, Mamo K, Geyid A. Common causes of Nosocomial Infections and their susceptibility patterns in two hospitals in Addis Ababa.Ethiop J Health Biomed Sci 2009; Vol 2:3-8.

12. Lily Catalano, Melissa Jean RB and EM. Best Practices and Considerations for Wound Care. Natl Heal Care. 2017;21(1):12-3.

13. BaMohammed A. An Observational Study on Wound Dressing Performance among Nurses in Adult Units Quality Indicator Specialist. Nurs Res Clin Pract Manag. 2018;7(3):1-6.

14. Nkamare MB. An assessment of wound dressing by nursing personnel at olabisi university teaching hospital. cont j nurs sci. 2013;5(1):21-4.

15. Dr. Haftu Berhe *Yohannes Tesfay Abebe and Hagos Tsega brhan. Nurses' knowledge, practice and associated factors regarding postoperative wound care of hospitalized pediatric patients. Int $\mathrm{J}$ Dev Res. 2015;8(10):1.

16. Musa MHMT. Assessment of Nurses' Performance Regarding Postoperative Wound Care in Khartoum State. Wounds uk. 2015;3(2):4.

17. Mccluskey P, Mccarthy G. Nurses' competence in wound management. 2017;(June 2012).

18. Farrow NE, Soares KC, Hicks CW, Rodriguez-unda N, Poruk KE, Cornell P, et al. Postoperative abdominal wound care. 2015;89-96.

19. Atiyah HH, Khudhur KM. Evaluation of nurses' practices toward postoperative wound dressing in surgical wards. Iraqi Natl J Nurs Spec. 2012;25(1):29.

20. Andrian T, Eriksen D, Wound Management for post operative Patients. 2014: 23-27.

\section{Figures}




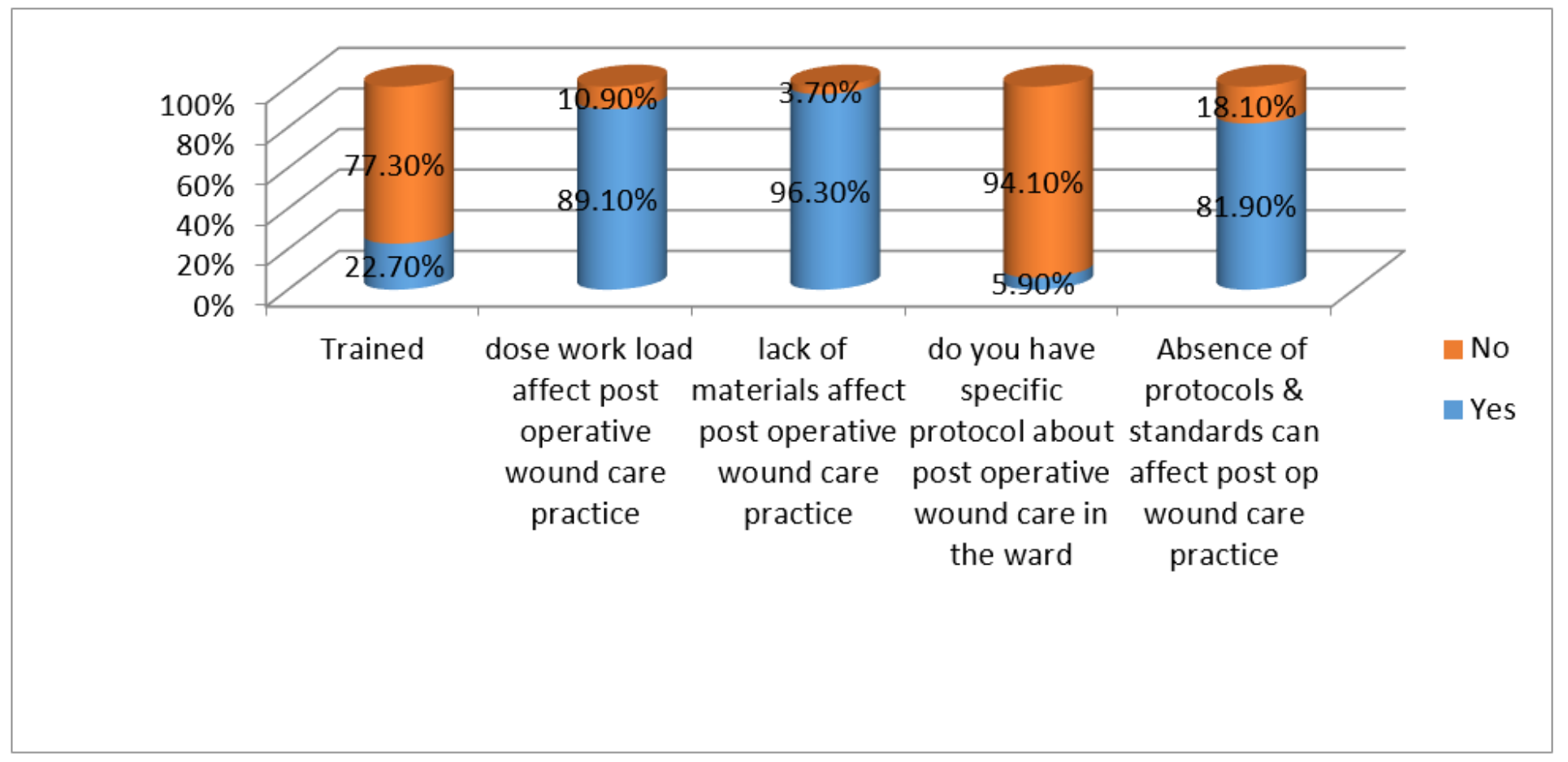

\section{Figure 1}

Institutional related associated factors 